\title{
Policy Research Perspectives
}

\section{Updated Data on Physician Practice Arrangements: For the First Time, Fewer Physicians are Owners Than Employees}

\author{
By Carol K. Kane, PhD
}

\section{Introduction}

Using data from the American Medical Association's (AMA's) Physician Practice Benchmark Surveys, this Policy Research Perspective (PRP) describes the practice arrangements of physicians between 2012 and 2018. The Benchmark Surveys include physicians who provide at least 20 hours of patient care per week, are not employed by the federal government, and practice in one of the 50 states or the District of Columbia.

As discussed in a previous report on this topic (Kane, 2017), 2016 was the first year in which less than half of practicing physicians (47.1 percent) had an ownership stake in their practice. With this report a new milestone has been reached-2018 marked the first year in which there were fewer physician owners (45.9 percent) than employees (47.4 percent). While these two events are notable, they reflect, as this PRP will discuss, the continuation of a longer-term trend.

The Benchmark Surveys also indicate that the distribution of physicians continues to slowly shift from practices that are very small in size to those that are very large. Between 2012 and 2018 the percentage of physicians in practices with 10 or fewer physicians dropped from 61.4 percent to 56.5 percent with much of that change driven by a shift away from solo practice.

In addition to changes in practice size, practice ownership is shifting away from physician-owned practice ("private practice") and toward working directly for a hospital or for a hospital-owned practice. Although this change is ongoing, it has been moving more slowly since 2014 than between 2012 and 2014. While the percentage of physicians working in physician-owned practices was lower in 2018 than in 2012 (54.0 percent compared to 60.1 percent) more than half of that decrease occurred in the first two years of that period.

New this year, this report includes a more in-depth look at private practice, including the size of those practices and a discussion of how that type of ownership structure varies across physician specialty. 


\section{Study data and methods}

The AMA's Physician Practice Benchmark Surveys are nationally representative surveys of postresidency physicians who provide at least 20 hours of patient care per week, are not employed by the federal government, and practice in one of the 50 states or the District of Columbia. The Benchmark Surveys have been conducted in every even year starting in 2012. The samples for the last three surveys were drawn from the M3 Global Research panel. ${ }^{1}$ At the time of the 2018 Benchmark Survey there approximately 39,000 verified physicians in the M3 panel who met the survey eligibility criteria and who were "active" according to criteria of the International Organization for Standardization (ISO).

Physicians were selected for participation in the 2018 Benchmark Survey based on Masterfile variables present in the M3 data indicating they had the characteristics described above. ${ }^{2}$ Those physicians received an email invitation from M3 that included a unique link to the survey website. Upon starting the survey, each physician was presented with a series of screener questions to ensure that he or she was in the sample frame. ${ }^{3}$ The survey was conducted in September 2018 and the final data included 3500 physicians with a response rate of 36 percent.

Weights for the survey were constructed by NORC at the University of Chicago to reflect the probability of selection from the M3 panel into the sample, and to adjust for non-resolution of eligibility status, differences between respondents and non-respondents, and differences between the distributions of the sample respondents and the population. Using eligible physicians in the AMA Masterfile as the population, weights took into account specialty, age, gender, whether the physician was an AMA member, present employment, and census region. All estimates presented here are weighted.

\section{Measurement of practice arrangements in the Benchmark Surveys}

The Benchmark Surveys collect information on four aspects of physician practice arrangements:

- whether physicians are owners, employees or independent contractors with their main practice (employment status);

- the type of practice that they work in;

- the number of physicians in their main practice (practice size); and

- the ownership structure of their main practice.

\footnotetext{
1 The 2012 sample was drawn from the ePocrates panel. See Kane and Emmons (2013) for more information on the 2012 Benchmark Survey.

2 Established by the AMA in 1906, the Masterfile includes significant education, training and professional certification information on virtually all Doctors of Medicine (MD) and Doctors of Osteopathic Medicine (DO) in the United States, Puerto Rico, Virgin Islands and certain Pacific Islands. See https://www.amaassn.org/physician-data-privacy for more information.

${ }^{3}$ Of the physicians in the who entered the survey, 5.5 percent were found to be ineligible. Federal employment was given most often as a reason for ineligibility, followed by seeing patients for fewer than 20 hours per week. That information is not available in the Masterfile.
} 
During the survey, physicians self-identify whether they are owners, employees, or independent contractors in their main practice. In addition, they are asked which one of nine categories best describes their main practice: solo practice, single specialty group practice, multi-specialty group practice, faculty practice plan, hospital, ambulatory surgical center, urgent care facility, health maintenance organization ( $\mathrm{HMO}$ )/managed care organization (MCO), and medical school.

Physicians who indicate that their main practice is a hospital are asked to clarify whether they work directly for a hospital or for a practice owned by a hospital. Physicians who respond that they work directly for a hospital fall under the "direct hospital employee/contractor" category in the exhibits in this PRP. Physicians who respond that they work for a practice owned by a hospital are asked a second time to identify their practice type (this time excluding the hospital category), and are categorized according to that response.

For practice ownership structure, physicians are presented with five options: wholly owned by one or more physicians in the practice, wholly owned by a hospital/hospital system, jointly owned between physicians and a hospital/hospital system, wholly owned by an HMO/MCO, and wholly owned by a notfor-profit foundation. Physicians who fall into the direct hospital employee/contractor category for practice type remain in that category for practice ownership structure. The practice type and the ownership structure questions both allow for fill-in responses.

Some of the practices arrangement estimates in this report are also presented for 12 large specialty groups. It should be noted that even within these groups there are many different subspecialties (over 250 in the aggregate) each of which may have slightly different practice arrangement patterns than the specialty group at large. The twelfth "other" specialty group includes specialties not elsewhere categorized.

\section{Employment status}

2018 was the first year in which fewer patient care physicians had an ownership stake in their practice (45.9 percent) than were employees (47.4 percent) (Exhibit 1). Seven percent of physicians were independent contractors, a share that has fluctuated between 4 and 7 percent since the early 1980s (Kane, 2015).

Since the first Benchmark Survey in 2012, the share of physicians who are owners has fallen by more than 7 percentage points-it was 53.2 percent in 2012. Data from earlier AMA physician surveys indicate that this share fell almost continuously between the early 1980s and the mid-1990s (75.8 percent in 1983, to 72.1 percent in 1988, and 57.7 percent in 1994) (Kletke, Emmons, and Gillis, 1996) with somewhat of a leveling off through 2007/2008 (Kane and Emmons, 2013). Thus, the more recent data from the Benchmark Surveys are not indicative of a new trend, but rather the continuation of one that has been ongoing, albeit at different rates, for at least 35 years.

Younger physicians and women physicians are less likely to be owners than their older and their male colleagues (Exhibit 2). In 2018, ownership ranged from 25.5 percent among physicians under the age of 40 to 54.3 percent among physicians age 55 and older. Thirty-four percent of women physicians were owners compared to 52.1 percent of men. 
There is a wide spread across specialties in the percentage of physicians who are owners (Exhibit $3)$. More than half of physicians in four specialty groups were owners in 2018: surgical subspecialties (64.5 percent), obstetrics/gynecology (53.8 percent), internal medicine subspecialties (51.7 percent), and radiology (50.7 percent). These specialties typically top the list for relatively high ownership percentages. Lowest on the list is emergency medicine, a specialty in which 26.2 percent of physicians were owners. That was also the specialty with the highest share of physicians who were independent contractors (27.3 percent). With the exceptions of anesthesiology and psychiatry, where around 12 percent of physicians were contactors, the contractor percentage in all other specialties was under 10 percent.

In most specialties, employment was fairly common, and the range across specialties was narrower than that for ownership. Even in surgical subspecialties, which had the lowest percentage, 33.7 percent of physicians were employed. In all other specialty groups more than 40 percent, and sometimes more than 50 percent of physicians (family practice, pediatrics, "other," and general surgery) were employed.

The specialty differences in employment status are one of several factors that contribute to the gender differences observed in Exhibit 2. Women tend to practice in specialties with relatively high rates of employment. For example, in 2018 around 17 percent of women physicians were pediatricians compared to 7 percent of men. ${ }^{4}$ Pediatrics has always been characterized by higher than average shares of employed physicians. Even in the mid-1980s when the physician workforce was 85.4 percent male (Randolph, Seidman, and Pasko, 1996), 32.1 percent of pediatricians were employed compared to 25.7 percent of physicians across all specialties (Gonzalez and Emmons, 1986). Second, women physicians are, on average, younger than male physicians. In 2018 about 22 percent of women physicians were under the age of 40 compared to 12 percent of men. ${ }^{5}$ Younger physicians have always been more likely to be employed than older physicians (Kletke, Emmons, and Gillis, 1996). Third, women's relatively recent entry into the physician workforce has occurred during a period when employment has become increasingly the norm.

\section{Practice type}

The plurality of physicians (42.8 percent) belonged to single specialty groups in 2018 (Exhibit 1). This share has been stable since 2014. Twenty-five percent of physicians belonged to multispecialty groups. Again, there has been little change in this share since 2014. Eight percent of physicians were employed directly by or contracted directly with a hospital, a share that has increased from 5.6 percent in 2012. The practice type in which there has been the most change is solo practice. The share of physicians in solo practice decreased from 18.4 percent to 14.8 percent between 2012 and 2018.

As observed in previous years of the Benchmark Surveys, there are specialty-level differences in the types of practices to which physicians belong (Exhibit 4). Nonetheless, single specialty practice accounts for more physicians than any other practice type in every specialty except general internal medicine. General internists' single specialty share of 27.8 percent was the lowest of any physician

\footnotetext{
${ }^{4}$ Author's calculation based on Masterfile data as of August 2018.

${ }^{5}$ Author's calculation based on Masterfile data as of August 2018.
} 
specialty. At the other end of the spectrum, more than half of radiologists, anesthesiologists, and obstetricians/gynecologists belonged to single specialty groups.

General internal medicine was the only specialty in which more than 30 percent of physicians ( 36.1 percent) were in multi-specialty groups. In four other specialties (pediatrics, subspecialties in internal medicine, family practice, and general surgery) at least 25 percent but no more than 30 percent of physicians belonged to a multi-specialty practice.

Psychiatry, at 28.1 percent, had the highest share of physicians in solo practice, a share well above that in other specialties. The next highest share was 19.9 percent in general internal medicine.

There are only a few specialties where hospitals directly employ or directly contract with a significant share of physicians. Emergency medicine is the clear outlier, with 23.3 percent of physicians in this practice type. Next highest are radiology and anesthesiology at 12.8 percent and 11.8 percent, respectively.

While there is some variation from year to year, there have been similar patterns across specialties in previous years of the Benchmark Surveys (Kane and Emmons, 2013; Kane, 2015; Kane, 2017).

\section{Practice size}

Although the majority of physicians still work in small practices, this share has fallen slowly but steadily since 2012. In 2018, 56.5 percent of physicians worked in practices with 10 or fewer physicians compared to 61.4 percent in 2012 (Exhibit 5). This change has been predominantly driven by the shift away from very small practices, especially solo practice. Over time, there has been a redistribution of physicians toward very large practices (with 50 or more physicians) with little change in the shares of physicians who practice in mid-sized practices (with 11 to 24 and 25 to 49 physicians). The percentage of physicians in practices with 50 or more physicians increased from 12.2 percent in 2012 to 14.7 percent in $2018 .^{6}$

There is a stark difference between the practice sizes of physicians in single and multi-specialty groups (Exhibit 6). In 2018, 38.5 percent of physicians in single specialty groups worked in practices with five or fewer physicians and 7.5 percent in practices of at least 50 . The distribution of physician in multi-specialty practices was almost the exact opposite: 9.1 percent of physicians in multispecialty practices worked in practices with five or fewer physicians, and 37.0 percent in practices with at least 50 physicians.

\footnotetext{
${ }^{6}$ For each year, the percentage of physicians who are direct hospital employees/contractors is slightly larger in Exhibit 5 than in Exhibits 1 and 7 (e.g., 8.5 percent compared to 8.0 percent in 2018). A few (less than 5 percent) respondents did not know how many physicians were in their practice and are excluded from the estimates in Exhibit 5. Because this makes the denominator in the practice size percentages smaller, it pushes the direct hospital employee/contractor percentage up compared to that in Exhibits 1 and 7.
} 


\section{Practice ownership structure}

Although the share is falling, more than half of physicians, 54.0 percent in 2018 , continue to work in practices that are wholly owned by physicians (Exhibit 7), sometimes referred to as "private practice." This share is statistically lower than that of 2012 (60.1 percent) and 2014 (56.8 percent), but not that of 2016 (55.8 percent). More than half of the 2012 to 2018 shift away from physicianowned practice occurred during the first two years of that period.

It's important to note that physician-owned practices include a wider scope of physicians than just those with an ownership stake in the practice. In addition to the practice owners (41.1 percent of all physicians), this category also includes the employed physicians (10.0 percent) and independent contractors (3.0 percent) who work for them. The sum of these three shares accounts for the 54.0 percent of physicians who work in physician-owned practices. ${ }^{7}$

Concurrent with the 2012 to 2018 decrease in the share of physicians in physician-owned practices, the share of physicians working directly for a hospital or in a practice at least partly owned by a hospital increased. Direct employment by/direct contracting with a hospital increased from 5.6 percent to 8.0 percent, and the share of physicians in hospital-owned practices increased from 23.4 percent to 26.7 percent. In the aggregate, 34.7 percent of physicians worked either directly for a hospital or in a practice at least partly owned by a hospital in 2018, up from 29.0 percent in 2012.

Across the 12 specialty groups, the percentage of physicians in practices that were physician-owned ranged from a low of 38.2 percent in emergency medicine to a high of 72.2 percent in the surgical subspecialties (Exhibit 8). The next highest shares were around 60 percent for obstetrics/gynecology and "other," and the next lowest was 44.7 percent for psychiatry. The remaining seven specialties had physician-owned practice shares in the range of 49.1 percent to 57.1 percent.

As Exhibit 9 illustrates, physician-owned practices are much smaller than hospital-owned practices. Just under 75 percent of physicians in physician-owned practices, but only 41.0 percent of physicians in those that were hospital-owned, said that their practice included 10 or fewer physicians. In contrast, only 8.6 of physicians in physician-owned practices, but more than 25 percent of physicians in those that were hospital-owned, said that their practice included 50 or more physicians. Combining this information with that from Exhibit 7, 40.0 percent of physicians worked in a practice that was both small (10 or fewer physicians) and physician-owned. ${ }^{8}$

\section{Discussion}

Based on data from the AMA's Physician Practice Benchmark Surveys, this Policy Research Perspective describes physicians' employment status, and practice size, type, and ownership

\footnotetext{
${ }^{7}$ Referring back to Exhibit 1, 45.9 percent of physicians were owners in 2018 . But, only 41.1 percent were owners in physician-owned practices. The remaining owners (4.8 percent of physicians) had ownership stakes in practices that were either jointly owned with a hospital or whose practice had some other type of ownership structure.

854.0 percent of physicians were in physician-owned practices (Exhibit 7). 74.7 percent of physicians in those practices were in groups with 10 or fewer physicians (Exhibit 9). 74.7 percent of 54.0 percent is 40.0 percent.
} 
structure between 2012 and 2018. One of the more dramatic changes over this six-year span was in employment status. The share of physicians who were owners fell from 53.2 percent to 45.9 percent, a drop of more than 7 percentage points. Due to this swing, for the first time in 2018 there were fewer physician owners than employed physicians (47.4 percent). The remaining physicians (6.7 percent) were independent contractors. Changes of this magnitude are not, however, unprecedented. Between 1988 and 1994, also a six-year span, ownership fell from 72.1 percent to 57.7 percent-a 14.4 percentage point shift (Kletke, Emmons, and Gillis, 1996).

Between 2012 and 2018 there was a redistribution of physicians from smaller practices, especially solo practice, to those that were very large. The percentage of physicians in solo practice fell from 18.4 percent in 2012 to 14.8 percent in 2018. As with employment status, there were even larger shifts in the late 1980s and early 1990s. In the six-year period between 1988 and 1994 the percentage of physicians in solo practice fell by almost 10 percentage points, from 38.6 percent to 29.3 percent.

In the research that examined shifts away from ownership and solo practice in the 1980s and early 1990s it was said, "if current trends persist, a majority of physicians will be employees in the very near future" (Kletke, Emmons, and Gillis, 1996). Given that only now has the point been reached where the number of employed physicians exceeds the number of owner physicians, caution should be taken in assuming current trends will continue indefinitely. One motivation given for the shifts toward larger practices (which typically have a higher employee to owner ratio) during the 1980s and 1990s was the desire to slow health care spending growth. Notably, in the current health care system, the ability to participate in new models of care (e.g., accountable care organizations) and the related goals of improving efficiency in the delivery of health care, reducing spending growth, and improving quality are factors in practice consolidation and integration with hospital systems. Just as shifts in physician practice arrangements stalled after the early 1990s, should evolving models of care not deliver on their theoretical savings or improvements, that might put a break on consolidation.

With regard to practice type, many more physicians belonged to single specialty groups (42.8 percent) than multi-specialty groups (25.2 percent) in 2018. Eight percent were employed directly by or contracted directly with a hospital and, as mentioned, 14.8 percent were in solo practice. The remaining 9.2 percent of physicians worked in a variety of other practice types.

For ownership structure, more than half of physicians (54.0 percent) worked in a physician-owned practice (sometime referred to as "private practice") in 2018 either as an owner, employee, or contractor. Although this share fell from 60.1 percent in 2012, the trend away from physician-owned practice and toward working directly for a hospital or for a hospital-owned practice appears to be slowing -more than half of that shift occurred in the first two years of that period.

Physicians in physician-owned practices report much smaller practice sizes than physicians in hospital-owned practices. In 2018, 74.7 percent of physicians in physician-owned practices worked in practices with 10 or fewer physicians compared to 41.0 percent of physicians in hospital-owned practices. Underscoring that many physicians are, or work for, small business owners, 40.0 percent of physicians worked in practices that were both small (10 or fewer physicians) and physicianowned. That this number is "so large" might be surprising. As is the case in other areas of research 
or public policy, reporting tends to focus on change rather than the status quo. The acquisition of one large practice by a hospital, for example, makes the news; the practice that remains independent does not.

As found in prior research, there were differences in practice arrangements across physician specialties. For employment status, ownership was most common among physicians in surgical subspecialties (64.5 percent) and least common among physicians in emergency medicine (26.2 percent). In that latter specialty, more than one-quarter of physicians were independent contractors, a share that was more than 10 percentage points higher than that of any other specialty.

Single specialty practice is the dominant practice type in almost all specialties. In fact, in every specialty except general internal medicine, more physicians worked in single-specialty practices than in any other practice type. Psychiatry, at $\mathbf{2 8 . 1}$ percent, had the highest share of physicians in solo practice. There were only a few specialties in which hospitals directly employed or contracted directly with a significant share of physicians. Emergency medicine was the clear outlier, with 23.3 percent of physicians in this practice type.

Mirroring the results for employment status, physician-owned practices accounted for the largest share of physicians in the surgical subspecialties (72.2 percent) and the smallest in emergency medicine (38.2 percent). Again, it's important to note that physician-owned practices include the owners of those practices as well as the employed physicians and independent contractors who work for them. 


\section{References}

Gonzalez, ML. Emmons, DW. Socioeconomic characteristics of medical practice, 1986. Chicago (IL): American Medical Association; 1986.

Kane, CK. Emmons, DW. New data on physician practice arrangements: private practice remains strong despite shifts toward hospital employment [Internet]. Chicago (IL): American Medical Association; 2013. Policy Research Perspective 2013-2 [cited 2019 Apr 26]. Available from https://www.ama-assn.org/sites/ama-assn.org/files/corp/media-browser/premium/health-policy/prpphysician-practice-arrangements $0 . p d f$

Kane, CK. Updated data on physician practice arrangements: inching toward hospital ownership [Internet]. Chicago (IL): American Medical Association; 2015. Policy Research Perspective 2015-3 [cited 2019 Apr 26]. Available from https://www.ama-assn.org/sites/ama-assn.org/files/corp/mediabrowser/premium/health-policy/prp-practice-arrangement-2015.pdf

Kane, CK. Updated data on physician practice arrangements: physician ownership drops below 50 percent [Internet]. Chicago (IL): American Medical Association; 2017. Policy Research Perspective 2017-2 [cited 2019 Apr 26]. Available from https://www.ama-assn.org/sites/amaassn.org/files/corp/media-browser/public/health-policy/PRP-2016-physician-benchmark-survey.pdf

Kletke, PR. Emmons, DW. Gillis, KD. Current trends in physicians' practice arrangements: from owners to employees. JAMA. Chicago (IL): American Medical Association; 1996;276(7):555-560 [cited 2019 Apr 26]. Available from https://jamanetwork.com/journals/jama/fullarticle/406731.

Randolph, L. Seidman, B. Pasko, T. Physician characteristics and distribution in the U.S. 1995/96 edition. Chicago (IL): American Medical Association; 1996. 
Exhibit 1. Distribution of physicians by employment status and type of practice ${ }^{1}$

\begin{tabular}{|c|c|c|c|c|}
\hline & 2012 & 2014 & 2016 & 2018 \\
\hline \multicolumn{5}{|l|}{ Employment status } \\
\hline Owner & $53.2 \% a$ & $50.8 \% a$ & $47.1 \%$ & $45.9 \%$ \\
\hline Employee & $41.8 \%{ }^{a}$ & $43.0 \%$ a & $47.1 \%$ & $47.4 \%$ \\
\hline \multirow[t]{2}{*}{ Independent contractor } & $5.0 \%{ }^{a}$ & $6.2 \%$ & $5.9 \%$ & $6.7 \%$ \\
\hline & $100 \%$ & $100 \%$ & $100 \%$ & \\
\hline \multicolumn{5}{|l|}{ Type of practice } \\
\hline Solo practice & $18.4 \%$ a & $17.1 \%{ }^{a}$ & $16.5 \% \mathrm{c}$ & $14.8 \%$ \\
\hline Single specialty group & $45.5 \% b$ & $42.2 \%$ & $42.8 \%$ & $42.8 \%$ \\
\hline Multi-specialty group & $22.1 \%{ }^{a}$ & $24.7 \%$ & 24.6 & $25.2 \%$ \\
\hline $\begin{array}{l}\text { Direct hospital } \\
\text { employee/contractor }\end{array}$ & $5.6 \%{ }^{a}$ & $7.2 \%$ & $7.4 \%$ & $8.0 \%$ \\
\hline Faculty practice plan & $2.7 \%$ & $2.8 \%$ & $3.1 \%$ & $3.0 \%$ \\
\hline \multirow[t]{2}{*}{ Other ${ }^{2}$} & $5.7 \%$ & $5.9 \%$ & $5.7 \%$ & $6.2 \%$ \\
\hline & $100 \%$ & $100 \%$ & $100 \%$ & $100 \%$ \\
\hline $\mathbf{N}$ & 3466 & 3500 & 3500 & 3500 \\
\hline
\end{tabular}

Source: Author's analysis of AMA Physician Practice Benchmark Surveys.

Notes: ${ }^{~}$ Significance tests are for changes between 2018 and each other year of the survey, within category. 'a' is $p<0.01$, 'b' is $p<0.05$, and ' $c$ ' is $p<0.10 .^{2}$ Other includes ambulatory surgical center, urgent care facility, $\mathrm{HMO} / \mathrm{MCO}$, medical school, and fill-in responses.

Exhibit 2. Age and gender differences in employment status (2018)

\begin{tabular}{|c|c|c|c|c|c|}
\hline & \multicolumn{2}{|c|}{ Gender } & \multicolumn{3}{|c|}{ Age } \\
\hline & Women & Men & Under $\mathbf{4 0}$ & 40 to 54 & $55+$ \\
\hline \multicolumn{6}{|l|}{ Employment status } \\
\hline Owner & $34.3 \%$ & $52.1 \%{ }^{a}$ & $25.5 \%$ & $46.1 \%{ }^{a}$ & $54.3 \%{ }^{a}$ \\
\hline Employee & $57.6 \%$ & $41.9 \%^{\mathrm{a}}$ & $69.8 \%$ & $47.2 \%{ }^{a}$ & $38.2 \%{ }^{a}$ \\
\hline \multirow{2}{*}{ Independent contractor } & $8.0 \%$ & $6.0 \%$ b & $4.7 \%$ & $6.7 \%$ & $7.5 \%$ a \\
\hline & $100 \%$ & $100 \%$ & $100 \%$ & $100 \%$ & $100 \%$ \\
\hline $\mathbf{N}$ & 1183 & 2317 & 695 & 1400 & 1405 \\
\hline
\end{tabular}

Source: Author's analysis of AMA 2018 Physician Practice Benchmark Survey.

Note: For gender, significance tests are between men and women. For age, significance tests are shown relative to the under 40 category. ' $a$ ' is $p<0.01$, ' $b$ ' is $p<0.05$, and 'c' is $p<0.10$. 


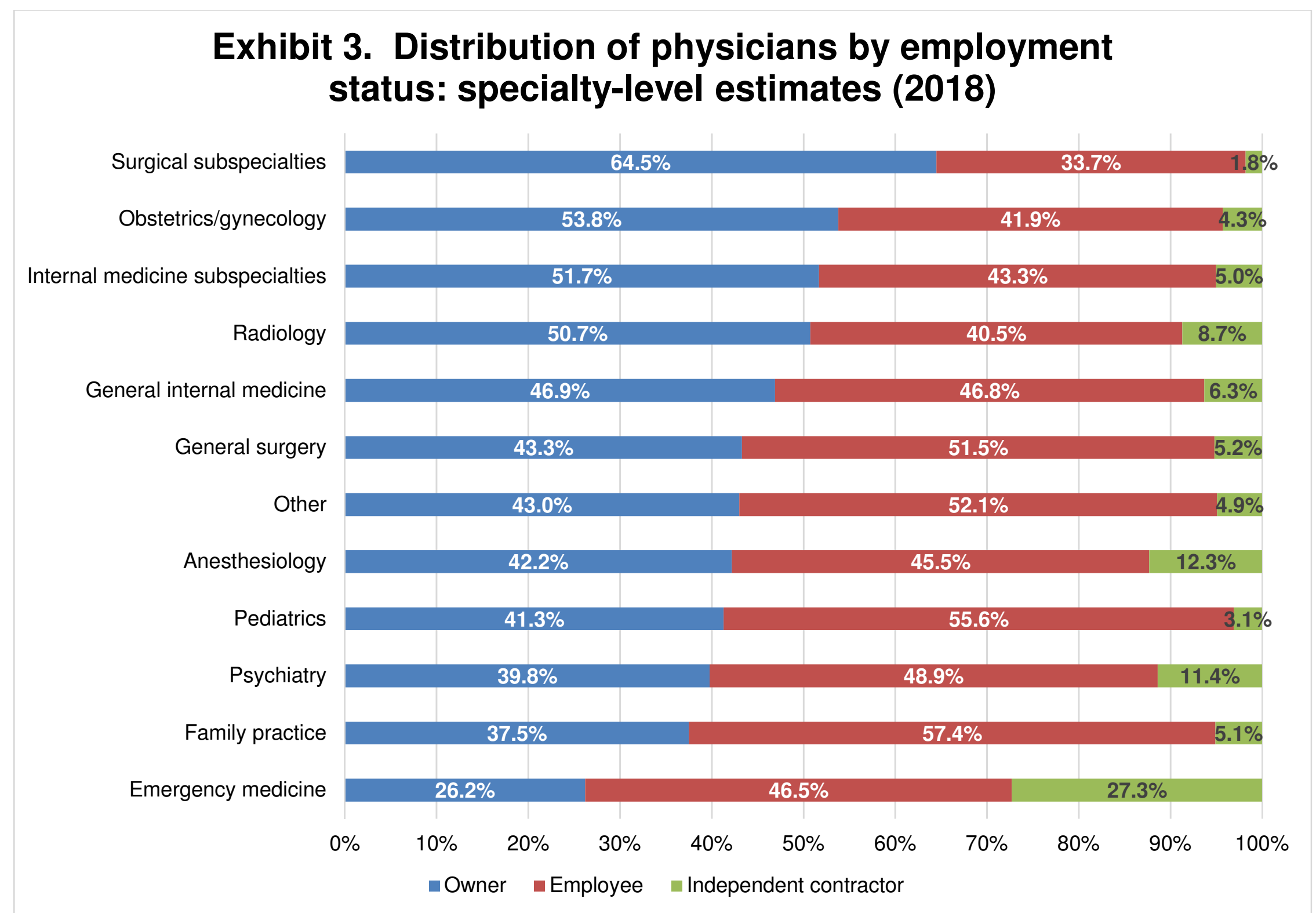

Source: Author's analysis of AMA 2018 Physician Practice Benchmark Survey. 


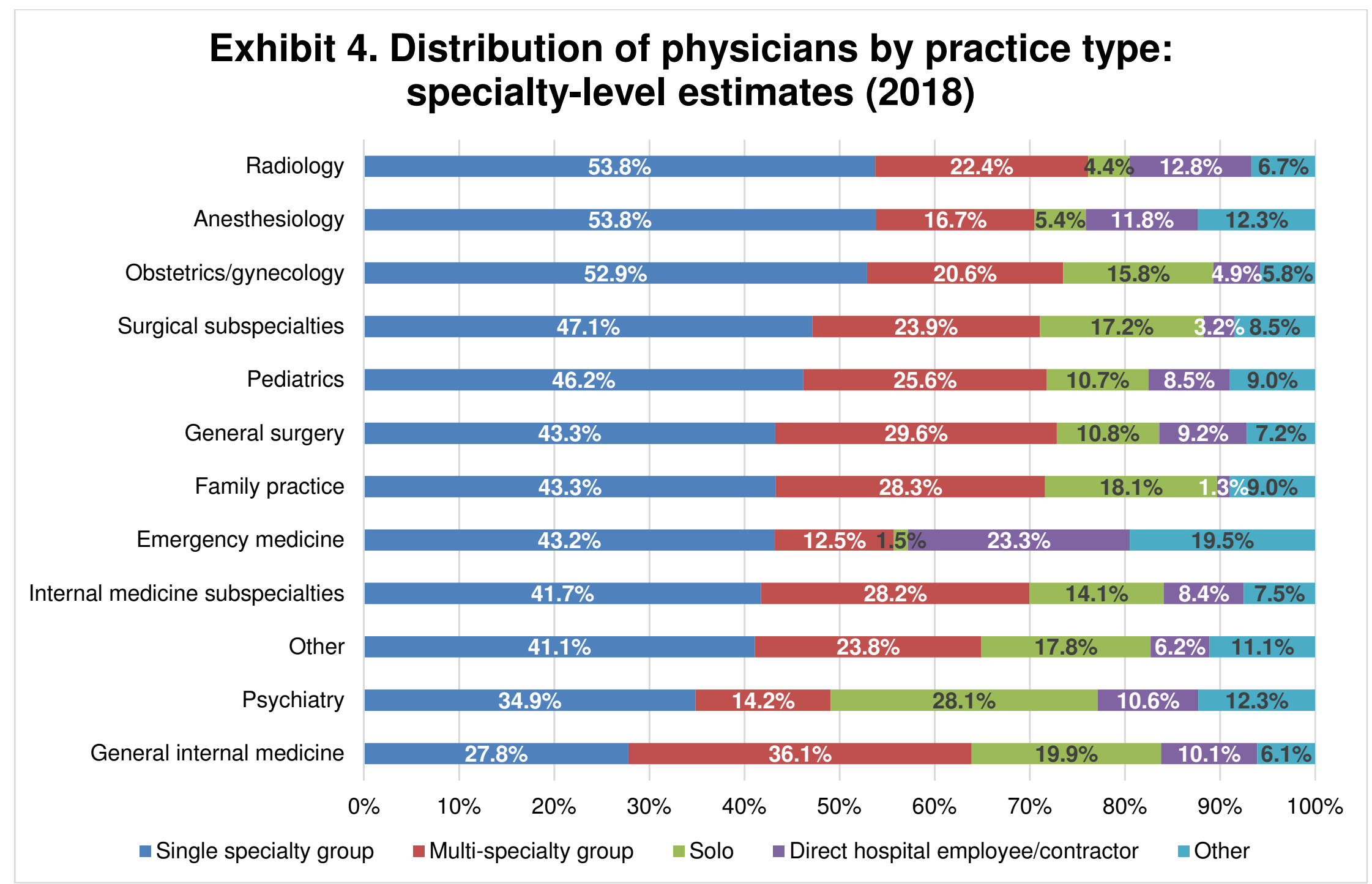

Source: Author's analysis of AMA 2018 Physician Practice Benchmark Survey.

Note: Other includes ambulatory surgical center, urgent care facility, $\mathrm{HMO} / \mathrm{MCO}$, medical school, faculty practice plan and fill in responses. 
Exhibit 5. Distribution of physicians by practice size ${ }^{1}$

\begin{tabular}{|c|c|c|c|c|}
\hline & 2012 & 2014 & 2016 & 2018 \\
\hline \multicolumn{5}{|c|}{ Number of physicians in practice } \\
\hline Less than 5 & $40.0 \% a$ & $40.9 \%{ }^{a}$ & $37.9 \%{ }^{c}$ & $35.7 \%$ \\
\hline 5 to 10 & $21.4 \%$ & $19.8 \%$ & $19.9 \%$ & $20.8 \%$ \\
\hline 11 to 24 & $13.4 \%$ & $12.1 \%$ & $13.3 \%$ & $12.7 \%$ \\
\hline 25 to 49 & $7.1 \%$ & $6.3 \% \mathrm{~b}$ & $7.4 \%$ & $7.6 \%$ \\
\hline $50+$ & $12.2 \%{ }^{a}$ & $13.5 \%$ & $13.8 \%$ & $14.7 \%$ \\
\hline \multirow[t]{2}{*}{$\begin{array}{l}\text { Direct hospital } \\
\text { employee/contractor }{ }^{2}\end{array}$} & $5.8 \%{ }^{a}$ & $7.4 \%$ & $7.7 \%$ & 8.5 \\
\hline & $100 \%$ & $100 \%$ & $100 \%$ & $100 \%$ \\
\hline $\mathbf{N}$ & 3326 & 3388 & 3381 & 3339 \\
\hline
\end{tabular}

Source: Author's analysis of AMA Physician Practice Benchmark Surveys.

Notes: ${ }^{1}$ Significance tests are for changes between 2018 and each other year of the survey, within category. 'a' is $p<0.01$ and ' $b$ ' is $p<0.05$. and ' $c$ ' is $p<0.10$. In addition to the tests shown in the exhibit, the percentage of physicians in practices with 10 or fewer physicians was statistically different between 2012 and 2018, and between 2014 and 2018 (both at $p<0.01$ ). ${ }^{2}$ See footnote 6 for an explanation of why, in each year, the percentage of physicians who are direct hospital employees/contractors in Exhibit 5 is different than in Exhibits 1 and 7.

Exhibit 6. Distribution of physicians in single and multi-specialty groups by practice size (2018)

\begin{tabular}{lc|c} 
& $\begin{array}{c}\text { Single specialty } \\
\text { group }\end{array}$ & $\begin{array}{c}\text { Multi-specialty } \\
\text { group }\end{array}$ \\
\hline Number of physicians in practice & $38.5 \%$ & $9.1 \%$ \\
Less than 5 & $31.3 \%$ & $23.0 \%$ \\
5 to 10 & $15.0 \%$ & $17.9 \%$ \\
11 to 24 & $7.6 \%$ & $12.9 \%$ \\
25 to 49 & $7.5 \%$ & $37.0 \%$ \\
$50+$ & $100 \%$ & $100 \%$ \\
\cline { 2 - 3 } & & 775 \\
\hline
\end{tabular}

Source: Author's analysis of AMA 2018 Physician Practice Benchmark Survey. 
Exhibit 7. Distribution of physicians by practice ownership structure ${ }^{1}$

\begin{tabular}{lc|c|c|c} 
& $\mathbf{2 0 1 2}$ & $\mathbf{2 0 1 4}$ & $\mathbf{2 0 1 6}$ & $\mathbf{2 0 1 8}$ \\
\hline Wholly owned by physicians & $60.1 \%^{\mathrm{a}}$ & $56.8 \%^{\mathrm{b}}$ & $55.8 \%$ & $54.0 \%$ \\
At least some hospital ownership & $23.4 \%^{\mathrm{a}}$ & $25.6 \%$ & $25.4 \%$ & $26.7 \%$ \\
$\quad$ Wholly owned by hospital & $14.7 \%^{\mathrm{c}}$ & $15.6 \%$ & $16.1 \%$ & $16.3 \%$ \\
$\quad$ Jointly owned by physicians and hospital & $6.0 \%^{\mathrm{a}}$ & $7.3 \%$ & $6.2 \%$ & $6.8 \%$ \\
$\quad$ Unknown whether wholly or jointly owned & $2.6 \%^{\mathrm{b}}$ & $2.7 \%^{\mathrm{c}}$ & $3.1 \%$ & $3.5 \%$ \\
Direct hospital employee/contractor & $5.6 \%^{\mathrm{a}}$ & $7.2 \%$ & $7.4 \%$ & $8.0 \%$ \\
Wholly owned by not-for-profit & $6.5 \%$ & $6.4 \%$ & $6.7 \%$ & $6.3 \%$ \\
foundation & $4.4 \%$ & $4.0 \%^{\mathrm{c}}$ & $4.7 \%$ & $4.9 \%$ \\
Other ${ }^{2}$ & $100 \%$ & $100 \%$ & $100 \%$ & $100 \%$ \\
& & & & \\
N & 3466 & 3500 & 3500 & 3500 \\
\hline
\end{tabular}

Source: Author's analysis of AMA Physician Practice Benchmark Surveys.

Notes: ${ }^{1}$ Significance tests are for changes between 2018 and each other year of the survey, within category. ' $a$ ' is $p<0.01$ and ' $b$ ' is $p<0.05$, and ' $c$ ' is $p<0.10$. In addition to the tests shown in the exhibit, the percentage of physicians in practices with at least some hospital ownership or who were a direct hospital employee/contractor was statistically different between 2012 and $2018(P<0.01), 2014$ and $2018(P<0.10)$, and 2016 and 2018 $(p<0.10) .{ }^{2}$ Other includes wholly owned by an $\mathrm{HMO} / \mathrm{MCO}$ and fill-in responses. 


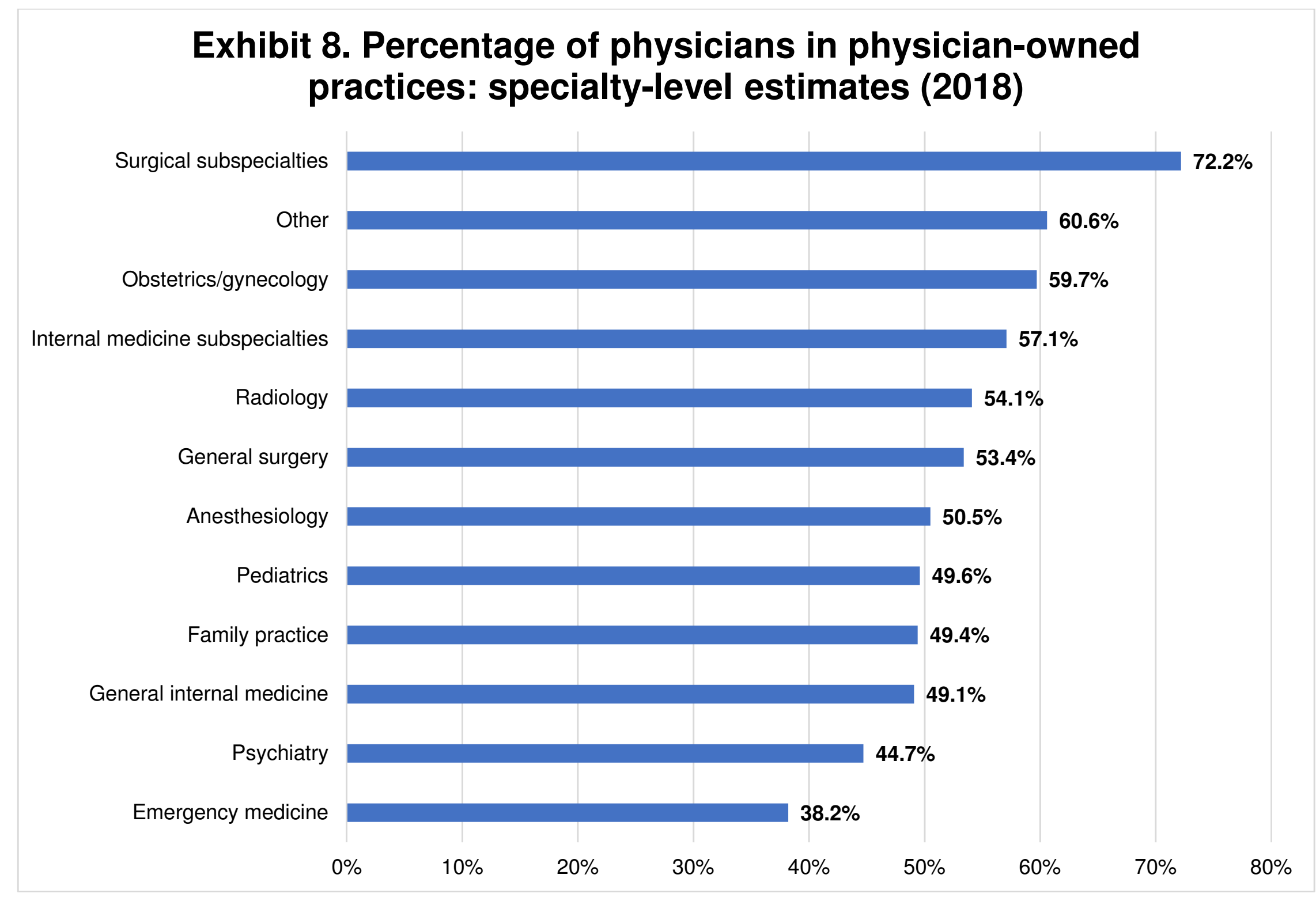

Source: Author's analysis of AMA 2018 Physician Practice Benchmark Survey. 
Exhibit 9. Distribution of physicians in physician- and hospital-owned groups by practice size (2018)

\begin{tabular}{lc|c} 
& $\begin{array}{c}\text { Wholly owned } \\
\text { by physicians }\end{array}$ & $\begin{array}{c}\text { At least some } \\
\text { hospital ownership }\end{array}$ \\
\hline Number of physicians in practice & & $16.2 \%$ \\
Less than 5 & $53.5 \%$ & $24.8 \%$ \\
5 to 10 & $21.2 \%$ & $20.0 \%$ \\
11 to 24 & $11.0 \%$ & $12.3 \%$ \\
25 to 49 & $5.7 \%$ & $26.8 \%$ \\
$50+$ & $8.6 \%$ & $100 \%$ \\
\cline { 2 - 3 } & $100 \%$ & 811 \\
\hline
\end{tabular}

Source: Author's analysis of AMA 2018 Physician Practice Benchmark Survey. 